We report here the development of severe anaemia due to erythroblastopenia in a patient receiving high doses of cephalothin.

A 67-year-old man had bilateral total hip prostheses for osteoarthritis, the right hip having been replaced in 1969 with a McKee-Farrar prosthesis and the left hip in 1970 with a Charnley prosthesis. In February 1974 an abscess developed in the anterolateral aspect of his right hip. Surgical exploration indicated that the abscess extended into the cavity of the hip joint and alongside the shaft of the femur. A heavy pure growth of greenzone streptococci was cultured.

The patient was initially treated with benzylpenicillin 5 megaunits intravenously six hourly. During the fourth week of treatment he developed During the fourth week of treatment he developed
a diffuse maculoerythematous skin rash which as thought to be due to penicillin allergy. As a result treatment was changed to lincomycin $0.5 \mathrm{~g}$ together with fusidic acid $1 \mathrm{~g}$ six-hourly by mouth. At the same time oral cephalexin was given, starting to $4 \mathrm{~g}$ daily up to a total of $28 \mathrm{~g}$ until the skin rash had completely faded. As there was no clinical evidence of cross-allergenicity these antibiotics were ceased and cephalothin intravenously $4 \mathrm{~g}$ wix-hourly was given with probenecid $2 \mathrm{~g}$ daily for six-hourly was given with probenecid $2 \mathrm{~g}$ daily for
a total of 22 days. The only other drug administered concurrently was diazepam, $2 \mathrm{mg}$ thrice daily.

His blood picture had been normal at the time of admission on 27 February. On 26 April his haemoglobin level had fallen to $8 \mathrm{~g} / 100 \mathrm{ml}$ and the reticulocyte count was less than $1 \%$. Bone marrow biopsy showed normal megakaryocytes and granulocytic series, but there were no red cell precursors. A diagnosis of pure red cell aplasia was made and all medications ceased.

The patient was transfused and six days later erythromycin was started. Reticulocytosis heralded bone marrow recovery and on 11 May, 15 days after repeat bone marrow biopsy showed a return of vigorous normoblastic erythropoiesis. The perivigorous normoblastic erythropoiesis. The peripheral blood picture was completely normal 27
days after ceasing cephalothin. The direct Coombs days after ceasing cephalothin. The direct Coombs
antiglobulin test was first performed 3 months after the aplastic episode and proved negative. It remained negative after incubation of the patient's red cells with varying concentrations of cephalothin.

The offending prosthesis was removed later and convalescence was uneventful. His renal function was normal throughout and appropriate radiological was normal throughout and appropriate radiological
studies excluded thymoma. During the 10 weeks studies excluded thymoma. During the 10 weeks
prior to the first bone marrow biopsy the only other drugs he had received and not mentioned in the above history were clindamycin $300 \mathrm{mg}$ sixhourly for three days approximately five weeks previously, mebhydrolin $1 \mathrm{~g}$ daily for three days for the skin rash, and three Doloxene (aspirin with
dextropropoxyphene) capsules given eight weeks previously.

Pure red cell aplasia is a rare condition and was reviewed recently by Teoh et al., ${ }^{4}$ who described three new cases, in one of which there was an associated thymoma. In another review Recker and Hynes ${ }^{5}$ noted an association between pure red cell aplasia and drug therapy in 40 patients; 21 cases occurred after treatment with chloramphenicol, and other drugs incriminated were sulphathiazole, arsphenamine, penicillin, phenobarbitone, isoniazid, chenopodium, phenylbutazone, tolbutamide and chlorpropamide, and phenytoin.

In our patient the return of erythropoiesis within 15 days of withdrawing cephalothin, diazepam, and probenecid strongly suggests that one of these three drugs was responsible for the erythroblastopenia. We have been unable to find any previous record of pure red cell aplasia being associated with any of these drugs. The clinical history and the references already cited ${ }^{1-3}$ raise the strong possibility of a causal link between ophalothin and red cell aplasia in our patient.-We are, etc.,

D. MaOCulloch

J. M. JACKSON J. VENERYS

Departments of Microbiology, Haematology, and Orthopaedics,
1 Davis, A., et al., Antimicrobial Agents and Chemotherapy, 1963, 3, 272

H. J., Fournal of the American Medical Asso Hiation, Journal of the
Mon, 203,601 .

3 Molthan, L., Reidenberg, M. M., and Eichman, M. F., New England łournal of Medicine, 1967, $277,123$.

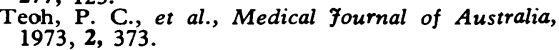
Recker, R. R., and Hynes, H. E., Archives of Internal Medicine, 1969, 123, 445.

\section{Nephrotic Syndrome in Chronic Lymphatic Leukaemia}

SIR,-We were interested to see the recent paper by Dr. J. R. E. Dathan and others on this subject (14 September, p. 655) since we have recently had two such patients under our care. Both, like the patients described by Dr. Dathan and his colleagues, were middle-aged men. The first patient was aged 64 and presented with a nephrotic syndrome. During investigations of this the diagnosis of chronic lymphocytic leukaemia was established. Renal biopsy showed typical membranous nephropathy on both electron microscopy and immunofluorescent study. He was treated with ahlorambucil, and though proteinuria has diminished and he no longer has oedema, proteinuria persisted and therapy was stopped after one year. This patient is discussed in more detail elsewhere. ${ }^{1}$ The second patient was a man of 57 years when chronic lymphocytic leukaemia was diagnosed. Because heavy proteinuria and ankle oedema were also present he was referred for renal biopsy. This showed sclerosing proliferative glomerulonephritis on light and electron microscopy; immunofluorescent studies were not done. Three years later his nephrotic syndrome persisted with a reduced glomerular filtration rate $(48 \mathrm{ml} / \mathrm{min})$. He reoeived no specific treatment.

There is no doubt that the association between neoplasia and a nephrotic syndrome with evidence of immune complex disorders is a strong one and that the commonest histological appearance in this association is membranous nephropathy. To date we ${ }^{1}$ have noted 27 patients whose nephrotic syndrome and neoplasm were diagnosed within one year of one another and who showed membranous nephropathy on renal biopsy (see table). Only a small number of patients have been reported with proliferative glomerulonephritis, though a number of patients with Hodgkin's disease and minimal ohanges have been described. ${ }^{2} 3$

Sites and Types of Neoplasia Associated with Membranous Nephropathy

\begin{tabular}{|c|c|c|}
\hline Neoplasm & $\begin{array}{c}\text { No. of } \\
\text { Patients } \\
\text { Reported }\end{array}$ & References \\
\hline $\begin{array}{l}\text { Carcinoma of bronchus } \\
\text { Carcinoma of colon or }\end{array}$ & 10 & $1,9-13$ \\
\hline $\begin{array}{l}\text { rectum } \\
\text { Codgkin's disease } \\
\text { Carcinoma of mouth or }\end{array}$ & 4 & $\begin{array}{l}1,5,6 \\
1,2,14,15\end{array}$ \\
\hline $\begin{array}{l}\text { pharynx. } \\
\text { Carcinoma of breast } \\
\text { Carcinoma of skin } \\
\text { Carcinoma of ovary } \\
\text { Carcinoma, origin unknown } \\
\text { Wilms's tumour .. }\end{array}$ & $\begin{array}{l}2 \\
1 \\
1 \\
1 \\
1 \\
1\end{array}$ & $\begin{array}{l}9 \\
10 \\
9 \\
9 \\
9 \\
1\end{array}$ \\
\hline $\begin{array}{c}\text { Chronic lymphatic } \\
\text { leukaemia }\end{array}$ & 1 & 1 \\
\hline
\end{tabular}

*The patient reported by Miller ${ }^{16}$ as having memsection considered to show minimal changes.

The possibility most investigated is that tumours might release antigens which in turn lead to circulating soluble complexes. ${ }^{4-6}$
In the leukaemias, particularly, the possibility of complexes formed with oncogenic virus antigen also arises. In addition to the evidence from mice that Dr. Dathan and his collsagues quote, the work of Sutherland and Mardiney ${ }^{7}$ is of interest. In a series of 90 patients dying from leukaemias and lymphomas, $10 \%$ showed granular IgG and C3 in their glomeruli, suggesting soluble complex deposition. Further, in two patients with chronic myelocytic leukaemia antigen consistent with the interspecies gs-3 portion of the feline leukaemia virus was demonstrated in kidney homogenates. Anderson and Jarrett $^{8}$ have also shown appearances resembling membranous nephropathy in feline leukaemia, though electron microscopy and immunofluorescence were not done in this study.

We would like to endorse Dr. Dathan's plea that patients with carcinomas, leukaemias, and lymphomas should be investigated for proteinuria regularly and, if it is found, that full investigation including renal biopsy should be performed.-We are, etc.,

Stewart CAMERoN C. S. OGG

Guy's Hospital,

1 Row, P. G., et al.y Membranous Nephropathy: Long-term Follow-up and Association with 2 Froom, D. W., et al., Archives of Pathology, 1972, 94, 547. Medicine, 1972, 52 , 699 .

Lewis, M. G., Loughridge, L. W., and Phillips, T. M., Lancet, $1971,2,134$.

Medicine, 1973, 289, 520 . Medicine. In press.

Sutherland, J. C., and Mardiney, M. R., fournal of the National Cancer Institute, 1973, 50, 633.
Anderson, L. J., and Jarrett, W. F. H., Research Anderson, L. J., and Jarrett, W. F. H.,
in Veterinary Science, 1971, 12, 179 .

Lee, J. C., Yamauchi, H., and Hopper, J., Annals of Internal Medicine, 1966, 64, 41.
oughridge, L. W., and Lewis, M. G., Lancet, 1971, 1,256.

Nephrologie, et al., fournal d'Urologie et de Asamer, H., Stuhlinger, W., and Dittrich, P., Deutsche medizinische Wochenshrift, 1974, 99, 573.

13 Higgins, M. R., Randall, R. E., and Still, 14 Hardin. J.' Gr., Coker, A. S., and Blanton, J. H., Southern Medical fournal, 1969, 62, 1111 . Castleman, B., Scully, R. E., and McNeely,
B U. New England fournal of Medicine, 1973, 289, 1241. G., Annals of Internal Medicine, 1967, Miller, D.

\section{Mouth Ulceration and Slow-release} Potassium Tablets

SIR,-Oral potassium supplements are one of the most commonly used medications in the pharmacopoiea. However, the ulcerogenic potential of high concentrations of potassium chloride in contact with mucosal surfaces is well known; both stenosis and perforation of the small intestine have been described.1 ${ }^{2}$ As a result of this, slow-release preparations of potassium chloride have been devised; these incorporate the active agent in a slow-release wax core. I report a case of mouth ulceration in a patient who sucked slow-release potassium tablets.

A 69-year-old European insulin-dependent diabetic was admitted to hospital in May 1974 with ischaemic heart disease, peripheral vascular disease, congestive cardiac failure, and pulmonary oedema. She responded to treatment with digoxin, insulin, diuretics, and potassium supplements in insulin, diuretics, and potassium

Two weeks after admission she was noticed to have developed multiple, well-demarcated, deep 